\title{
Sociologia e história
}

\section{na obra de José de Souza Martins}

William Héctor Gómez Soto*

Resumo: $O$ autor analisa a sociologia de José de Souza Martins, centrando a atenção em sua perspectiva teórica e seu método dialético. Martins escolhe como objeto aquilo que está à margem da sociedade e das ciências sociais, como, por exemplo, o destino das populações rurais, os sonhos dos trabalhadores das grandes cidades, a aparição do demônio numa fábrica e a vida cotidiana do homem simples. Discípulo de Florestan Fernandes, Martins dialoga com Marx e Lefebvre, dos quais toma duas noções fundamentais: a de menos-valia e a de resíduo. $\mathrm{O}$ autor deste artigo destaca que essas duas noções, aparentemente insignificantes, são a chave para compreender a contribuição de Martins. Na sociologia de Martins, o que está à margem e que é liminar não apenas é um tema como também, e principalmente, um recurso metodológico.

Palavras-chave: menos-valia, resíduo, sociologia, história, método dialético.
Recebido: 06.04.15

Aprovado: 18.02 .16 * Professor do curso
de ciências sociais
e do mestrado
em sociologia da
Universidade Federal
de Pelotas. <william.
hector@gmail.com>.

\section{Introdução}

A obra de José de Souza Martins não pode ser caracterizada como "sociologia histórica", porém em sua pesquisa sociológica há uma perspectiva particular que combina sociologia e história, o que confere uma das principais características de sua sociologia, ou seja, seu enraizamento nas condições históricas e nas peculiaridades da sociedade brasileira. A perspectiva que articula sociologia e história é uma tradição retomada por Martins de Karl Marx, Henri Lefebvre e Florestan Fernandes. É a partir da pesquisa empírica e histórica que Martins descobre as diferenças da sociedade brasileira em relação a outras sociedades, principalmente a inglesa, que foi a principal referência para os estudos de Marx.

Martins é crítico do que ele chama de sociologia da cópia e da importação, ou seja, da incorporação de teorias produzidas em outras condições históricas, e que são utilizadas ou transpostas sem crítica, para a sociedade brasileira. De Florestan Fernandes, Martins retoma o esforço de construir uma sociologia enraizada no processo histórico da sociedade brasileira e, desta forma, destacar suas particularidades e contradições. Por isso sua sociologia não se reduz a uma especialidade, como é a "sociologia histórica", a articulação entre história e sociologia forma parte do método adotado e que sintetiza sua crítica às importações de teorias produzidas em outras temporalidades. Não há nele nenhuma pretensão de afirmação de uma "sociologia nacional", muito pelo contrário, a sua sociologia é um amplo diálogo, rico e 
frutífero com uma grande diversidade de autores e teorias clássicas e contemporâneas. De forma criativa, Martins dialoga com esses diversos autores para construir uma sociologia enraizada. Herdeiro de Florestan Fernandes, percorre novos caminhos, descobre novos temas e, sobretudo, cria um estilo e um método particular de fazer sociologia.

\section{A dialética como método e o seminário sobre $O$ capital}

Martins utiliza criativamente o método de Marx - a dialética -, uma dialética viva, não esterilizada pelo dogmatismo; retorna a Marx, a seu pensamento, mas reconhece a Marx como pensador datado, humano, portanto com limites e, além disso, autor de uma obra inacabada e contraditória. Com o objetivo de apreender o método dialético, organizou, de 1975 a 1987, um seminário para estudar a obra de Marx; posteriormente, coordenaria um seminário para analisar a obra de Henri Lefebvre. Este último seminário durou seis anos (Martins, 1996b). Lefebvre é um pensador francês contemporâneo, cujo principal desafio foi atualizar o pensamento de Marx à luz das mudanças sociais ocorridas no último século. O filósofo e sociólogo francês traz novos temas e conceitos para a análise da sociedade contemporânea e, sobretudo, oferece-nos uma nova forma de abordagem para a explicação dos fenômenos sociais. Lefebvre é o sociólogo da vida cotidiana, da produção do espaço e da modernidade. Em sua vasta contribuição, é possível destacar a teoria e o método dos resíduos, que passando despercebida para os estudiosos lefebvrianos, ajuda-nos a compreender e a explicar a sociologia de José de Souza Martins. Voltaremos a essa questão com detalhes mais adiante.

Martins não é simplesmente influenciado por Lefebvre, ele estabelece um diálogo crítico com o sociólogo francês, apropriando-se principalmente de seu método, de sua concepção de historicidade, da coexistência de temporalidades diferentes. Martins explicita seu método e a perspectiva teórica de sua sociologia. É essa perspectiva teórica que dá coerência a sua sociologia. Em seu livro O cativeiro da terra (2010), Martins deixa claro o ponto de vista teórico e metodológico de sua sociologia, e nele é possível compreender sua concepção da história. Esse ponto de vista teórico fica explicitado nas suas próprias palavras:

Venho orientando a minha pesquisa teórica e empírica pelo problema da produção capitalista de relações não capitalistas de produção no marco da reprodução capitalista do capital de origem não capitalista (Martins, 2010: 19). 


\section{A reprodução das relações sociais}

Essa ideia é central para compreender a sociologia de Martins e, sobretudo, para mostrar sua inovação teórica. Assim, voltamos a Lefebvre que recuperou de Marx o conceito de reprodução das relações sociais capitalistas. Os seguidores de Marx prestaram pouca atenção a essa problemática, primeiro por causa de uma concepção mecanicista e quase automática da reprodução das relações sociais, através dos "aparelhos ideológicos do Estado"; mas também porque esperavam a derrubada iminente do capitalismo. Lefebvre (1973) defende a tese de que o capitalismo reproduz as relações sociais capitalistas, mas, ao mesmo tempo, produz novas relações sociais. Ou seja, não há só repetição e reprodução, mas também inovação e produção de novas relações sociais, como aquelas relacionadas com os variados tipos de economia solidária, de cooperação ou as vinculadas com iniciativas de sustentabilidade ambiental e social, de consumo consciente e novas formas de mercado. Portanto, o capitalismo é capaz de produzir novas relações sociais que Lefebvre encontra principalmente na vida cotidiana, mas também no espaço e no fenômeno urbano. Vale a pena chamar a atenção sobre a referência proposta por Lefebvre sobre a reprodução de relações tipicamente capitalistas, porém a pesquisa empírica e histórica que Martins realiza sobre as singularidades da formação da sociedade brasileira o conduz a novas conclusões e, desta forma, sua sociologia se constitui na continuidade da sociologia crítica e criativa de Florestan Fernandes interrompida pelo golpe militar de 1964.

\section{O golpe militar e a sociologia de Florestan Fernandes}

O golpe militar significou uma grave interrupção na formação da sociologia brasileira e em seus criativos e originais desdobramentos. Martins assim se refere a essa ruptura de continuidade da sociologia de Florestan Fernandes, provocada pelo golpe militar:

As cassações, que atingiram profundamente a Faculdade de Filosofia, interromperam uma história em andamento, tanto na pesquisa quanto no ensino, quanto, ainda, nas orientações temáticas de cursos e pesquisas (Martins, 2013: 42).

Esta ruptura provocou um vácuo de memória. Os professores cassados não voltaram com a anistia decretada pelo regime militar em 1979. "A ditadura conseguira quebrar a espinha dorsal da chamada 'escola sociológica da USP'" (Martins, 2013: 43). Martins é um representante dessa "geração órfã", como ele mesmo denomina a geração que perdeu seus professores, aqueles que tinham sido formados pela 
missão francesa que fundou a USP. Porém, ele não só dá continuidade às grandes preocupações sociológicas do grupo de Florestan Fernandes, mas provoca a renovação dos temas, da teoria e dos métodos. Nas condições adversas criadas pelo golpe militar, ele contribui para a diversificação e o enriquecimento da sociologia brasileira. Essa situação dramática é descrita por Martins:

$\mathrm{Na}$ antiga cadeira de Sociologia 1, de Florestan Fernandes, que fora a cadeira de Lévi-Strauss e, depois, de Roger Bastide, havia uma articulação temática, na pesquisa, decorrente de um projeto de estudo que Florestan elaborara, Economia e sociedade no Brasil [...]. Alguns temas se tornaram obsoletos da noite para o dia. Apesar de teoricamente sólida e original, internacionalmente reconhecida e respeitada, a sociologia brasileira que se fazia aqui na Faculdade, em torno de Florestan Fernandes, foi aos poucos sendo marginalizada em nome de modismos, sobretudo europeus. Hoje pensamos o Brasil com cabeça estrangeira (Martins, 2013: 45).

Após as cassações de Florestan Fernandes, Fernando Henrique Cardoso e Octávio Ianni, seus professores, Martins inicia sua longa e criativa carreira de pesquisador. Decide explorar a nova fronteira na região da Amazônia, onde as populações nativas estavam sendo expulsas.

A Amazônia - disse Martins - era e é a última fronteira do mundo, o último recanto da terra em que povos desconhecidos estavam na iminência de um contato catastrófico com as forças corrosivas e genocidas da chamada civilização ou, mais corretamente, da sociedade moderna (Martins, 2013: 252).

É nesse contexto de destruição da natureza, de eliminação e de escravidão das populações camponesas, que ele prolonga o esforço de Florestan Fernandes. Para Martins, o desafio dos cientistas era documentar esse processo violento de ocupação do território, pelo capital. Segundo ele, os antropólogos e os geógrafos já estavam no terreno buscando compreender o que estava acontecendo na Amazônia, porém o processo não tinha despertado o interesse dos sociólogos, precisamente porque, nas palavras dele:

Sociólogos se interessam por sociedades instituídas e organizadas e não propriamente por sociedades nascentes, ainda nos primeiros dias de formação e reformulação, que era o que ocorria na Região Amazônica. Uma sociedade velha que renascia e se reinventava no banho de sangue da anulação de regras sociais estabelecidas e criação das regras provisórias dominadas pela lei do mais forte (Martins, 2013: 253). 
O relevante está em que a análise desta situação tornava evidente - para Martins - os desencontros dos tempos históricos, as temporalidades diferentes e o ritmo desigual das relações sociais e, principalmente, a relevância metodológica daquilo que está à margem, na periferia. Isto é interessante, como veremos na sequência, porque expressa a originalidade do ponto de vista do sociólogo brasileiro e sua concepção não determinista e não linear da história. Como ele mesmo diz,

\begin{abstract}
coisa raramente perceptível em sociedades urbanas estabilizadas e secularizadas, com regras seguras e horizontes definidos. A sociedade da fronteira era um desafio na última oportunidade que se abria para o estudo sociológico desse momento do processo histórico numa sociedade nova (Martins, 2013: 253).
\end{abstract}

Foi fazer pesquisa de campo no Mato Grosso, no Pará e em Rondônia, regiões de tensões e conflitos, mas com dinâmicas distintas. Não só estudou os conflitos e as tensões sociais, mas também a criatividade e o imaginário dessas populações. E foi nelas, nesse contexto específico de hostilidade e enfrentamento, que descobriu os novos sujeitos sociais do processo histórico brasileiro. Ele não se refere só às populações indígenas, como novos sujeitos sociais da fronteira, mas também aos posseiros e aos trabalhadores rurais, os homens simples divididos entre o mundo tradicional e o mundo moderno. Ele chega à conclusão de que há uma nova cena histórica, distinta daquela presente na literatura e que marca uma distância profunda entre a academia e a vida cotidiana dessas populações. "O país que se discutia nos meios de acadêmicos estava bem longe do país que abrangia dois terços do território nacional" (Martins, 2013: 270).

Uma hipótese inicial, na elaboração da sua sociologia, contribui para entender que Martins não só prolonga as ideias, os temas e os métodos do grupo de Florestan Fernandes, mas também propõe novos problemas sociológicos e, principalmente, traz um ponto de vista original, a partir de uma perspectiva teórica e metodológica. Desde muito cedo, no fim dos anos 1960, Martins levanta novas hipóteses para explicar a sociedade brasileira. Contraria certo consenso vigente na academia - em relação à tendência inevitável do desaparecimento das relações arcaicas - ao mostrar que essas relações não são antagônicas com as relações capitalistas, ao contrário, desempenham um papel fundamental na reprodução ampliada do capital. Sua hipótese contém uma crítica explícita ao determinismo histórico, ou seja, à visão de que o desenvolvimento do capitalismo levaria à eliminação de relações sociais não capitalistas.

É precisamente na sua dissertação de mestrado, concluída em 1966, que Martins levanta essa hipótese, que se transforma em tese, após a pesquisa de campo. Esta 
ideia inicial é fundamental para compreender sua sociologia e entender como ele interpreta e explica a sociedade brasileira. Ideia que depois vai se enriquecendo ao longo de sua reflexão e, sobretudo, com a descoberta da obra de Henri Lefebvre. Em 1965, realiza uma extensa pesquisa na zona rural da Alta Sorocabana, da Baixa Mogiana e do Alto Paraíba, precisamente com o objetivo de analisar as repercussões das transformações sociais na agricultura, comparando a agricultura moderna e a agricultura tradicional (Martins, 1975).

O tema das mudanças sociais era central para o grupo de Florestan Fernandes, porém pensado em uma perspectiva diferente daquela proposta por Martins em sua pesquisa de mestrado. No grupo de Florestan, predominava a ideia de que havia uma resistência às mudanças sociais e às inovações por parte das populações tradicionais.

Preparei um projeto baseado na hipótese teórica oposta, em confronto com a sociologia da cadeira à qual eu me vinculara, a de Florestan. Minha hipótese era a de que a agricultura tradicional, não moderna, a que não seguia padrões de racionalidade econômica, porque baseada no mero costume, tinha uma função no próprio processo de acumulação de capital e, portanto, uma função moderna [...]. O tradicionalismo, em minha hipótese, não era anticapitalista, embora o agricultor estivesse distante do empresário de tipo weberiano. Ele não acumulava necessariamente, mas era peça decisiva no processo de acumulação e, portanto, da modernização, que viabilizava, mas da qual não se beneficiava (Martins, 2013: 33).

\section{O mundo tradicional e a modernidade}

Os resultados dessa pesquisa, publicados num dos primeiros livros de Martins com o título de Capitalismo e tradicionalismo, de 1975, constituem a base fundamental da crítica da razão dualista. Ao defender a tese de que as relações sociais "arcaicas", não capitalistas, não estariam em contradição antagônica com o capitalismo, mas que, ao contrário, cumpririam uma função no processo de acumulação do capital, Martins estava deslocando a discussão do moderno para o capitalismo, isto é, da problemática da resistência às mudanças, para a análise das particularidades históricas do capitalismo brasileiro. Esse giro é importante, porque representa um esforço para não considerar o capitalismo como mera abstração. Vale destacar que membros do grupo de Florestan Fernandes já tinham se esforçado no sentido de desvendar o caráter histórico do capitalismo brasileiro, mostrando suas contradições.

Nos anos 1960, Fernando Henrique analisa a contradição entre a forma mercantil da economia e as relações sociais baseadas no trabalho escravo, entendendo-a não como anomalia, mas como contradição constitutiva da realidade. 
A insistência de Martins sobre a importância da pesquisa empírica e histórica não é por acaso, é dela que surgem suas principais contribuições para a compreensão sociológica da sociedade brasileira. Em O cativeiro da terra (2010), critica as muitas interpretações que consideram que a transição do trabalho escravo para o trabalho livre adquiriu a forma de trabalho assalariado, como ocorreu em outros países. Martins mostra que essa transição se baseou em relações sociais não capitalistas. Essa mudança no modo de produção do capital se fez a partir da imigração de trabalhadores italianos e espanhóis, processo organizado pelas elites brasileiras que consideravam economicamente inviável continuar com a utilização do trabalho escravo.

Os mecanismos que garantiam a reprodução das relações sociais passaram da violência e do domínio sobre o corpo do escravo, para um mecanismo ideológico baseado na ilusão de que o trabalhador, através do sacrifício, da poupança, um dia se transformaria em proprietário. A produção da mais-valia, nas fazendas de café, se deu a partir de relações não capitalistas. Mesmo existindo, o salário não era relevante. O mais importante para os trabalhadores era a possibilidade real oferecida pelo fazendeiro para produzir seus bens de subsistência. Nas palavras de Martins:

\begin{abstract}
Também aí havia outro problema, envolvendo os vários autores que trataram da substituição do trabalho escravo pelo trabalho livre. Difundiu-se por médio deles a concepção de que o trabalho escravo fora substituído pelo trabalho assalariado e não simplesmente pelo trabalho do trabalhador juridicamente livre, mas não formalmente assalariado [...]. O trabalho escravo fora, na verdade, substituído pelo regime de colonato, que combinava várias relações arcaicas de trabalho, como a prestação gratuita de serviços, a renda em trabalho e a produção direta dos meios de vida. Só em pequena parte, essas modalidades de uso da terra foram complementadas pelo pagamento propriamente salarial da colheita de café pela família do colono (Martins, 2013: 37).
\end{abstract}

Como já foi dito anteriormente, há em Martins, desde o início de sua trajetória como pesquisador, uma preocupação com o método dialético, pela apropriação do método de Marx, e essa apropriação marca ao mesmo tempo a continuidade e a renovação da sociologia em relação ao grupo de Florestan Fernandes. Martins resgata um Marx datado e autor de uma obra, como já foi exposto, incompleta e desigual. O importante de Marx é o método - disse Martins -, apesar disso, ele utiliza em sua análise e interpretação da sociedade brasileira os conceitos centrais de Marx, como mais-valia, alienação, acumulação de capital e reprodução das relações sociais de produção. 


\section{A presença de Lefebvre}

A influência de Lefebvre marca um ponto de inflexão na sociologia de Martins. É essa influência que cria a possibilidade de abertura de sua sociologia para novos temas e enfoques metodológicos.

Fizemos em conjunto a leitura e releitura de boa parte da obra de Marx durante doze anos, às sextas-feiras de manhã, em semestres alternados. Terminado esse período, o seminário sobre o método dialético teve continuidade na leitura de um marxista de envergadura clássica, Henri Lefebvre, o autor de uma leitura propriamente sociológica da obra de Marx. O autor que trazia Marx cientista para o século XX. Lemos e analisamos boa parte da obra de Lefebvre nos seis anos seguintes. É Lefebvre quem propõe que a sociologia marxiana é uma coisa e o marxismo é outra [...]. Lefebvre dedicou especial interesse e atenção na linha, justamente, da sociologia marxiana e da sociologia clássica, à pesquisa empírica e a suas conexões com o trabalho teórico, à articulação entre método de investigação e método de explicação (Martins, 2013: 47).

Martins destaca a importância da pesquisa empírica em Lefebvre, um traço comum interessante entre os dois:

Sua obra interpretativa é toda marcada pela centralidade do empírico. Para realização das descobertas teóricas que estão nos fundamentos de seus livros sobre o espaço e a cidade, Lefebvre tornou-se motorista de táxi em Paris [...]. Foi por essa via que Lefebvre desvendou as tensões entre produção social e reprodução social, a reprodução ampliada de capital como reprodução ampliada de contradições sociais. Portanto, abriu o caminho para a compreensão sociológica da cotidianidade e do reprodutivo e, também, do âmbito desdobrado da revolução como revolução urbana e como revolução na vida cotidiana (Martins, 2013: 48).

A sociologia de Martins aborda uma ampla diversidade de temas, como estudos sobre as populações tradicionais, a vida cotidiana, o subúrbio, os movimentos sociais, os linchamentos, as contradições da modernidade, a questão agrária e a reforma agrária, entre outros, mas, longe de serem temas isolados, fazem parte de um conjunto coerente.

O que dá unidade a minha obra é a investigação da historicidade nas diferentes manifestações da vida social, isto é, a identificação das condições e fatores da mudança social nos diferentes âmbitos da realidade, mesmo na realidade mínima e cotidiana [...]. Oriento-me pela identificação do que é histórica e concretamente 
possível e dos obstáculos e cerceamentos à sua manifestação e realização. Dou continuidade, numa perspectiva peculiar, ao que foi o centro das preocupações teóricas e empíricas da chamada "Escola Sociológica de São Paulo", que teve em Florestan Fernandes o centro e a referência. A dialética, na orientação metodológica do resgate que dela faz Lefebvre, foi fundamental para dar a dimensão de conjunto aos meus livros e artigos [...]. Basicamente, interrogo a história e o possível que se escondem no cotidiano, no banal, no repetitivo e nas meras formas do aparente (Martins, 2013: 40).

\section{Uma sociologia da margem}

É nessa perspectiva que ele propõe uma nova sociologia, chamando a atenção para o que está no limite e à margem, como possibilidade explicativa das contradições da sociedade brasileira. O que está à margem, no limite, é o método explicitado e teorizado por Martins. Por isso, durante muito tempo, em sua trajetória, dedicou-se a estudar as particularidades do rural, do drama das populações na fronteira entre a tradição e a modernidade. Tomar o que está à margem como princípio metodológico é um traço marcante de sua sociologia.

E este é um aspecto compartilhado com Lefebvre, que valorizava a periferia como ponto de vista privilegiado de observação e análise. Aqui também existe uma ligação curiosa entre esse ponto de vista metodológico e a origem social de Martins e Lefebvre. Lefebvre se considerava da periferia da sociedade, ele nasceu na região dos Pirineus franceses, e adotava uma postura crítica em relação aos intelectuais de Paris. Para Lefebvre, "[...] la consciência periférica dirigida metodicamente permite alcanzar el conocimiento del centro y de la mundialidad" (Lefebvre, 1976: 58). Num de seus textos, Martins explora as semelhanças da origem social de Henri Lefebvre e Florestan Fernandes. A proposta metodológica de Martins surge explicitamente em 1975, coincidentemente com o início do seminário organizado por ele sobre o método dialético em Marx.

Afirma que quem está no limite tem uma visão crítica da sociedade, diferente de quem está integrado. As pessoas que estão no limite conseguem ver mais, ver além, por exemplo, as populações rurais, que são pessoas que estão num mundo dividido, em crise, num mundo tradicional ameaçado pelo mundo moderno.

Quem está nessa situação, vê o todo porque vê o que está acabando, vê que a sociedade é processo, movimento, transformação, finitude, mais do que estabilidade, permanência, estrutura (Martins, 2013: 59). 
Na sua sociologia, o tempo é cíclico, não linear. Na sua análise, o capitalismo brasileiro não elimina as formas sociais e culturais tradicionais. Essa ideia, como já foi mencionado, aparece no início da sua trajetória. Para ele, a sociedade brasileira é uma sociedade híbrida, de tempos sociais que se combinam e se misturam, uma característica da chamada modernidade. A modernidade é essa mistura de tempos que muitos denominam de pós-modernidade, mas não existe uma distinção clara e rígida entre modernidade e pós-modernidade. Essas relações sociais diversas, diferentes, que se combinam no capitalismo brasileiro, não são necessariamente contemporâneas, pertencem a temporalidades diferentes.

Nessa combinação de tempos históricos, não apenas se expressa o passado e o presente, mas também as possibilidades futuras. É no mundo rural que se encontra mais claramente essa diversidade de tempos históricos de relações sociais datadas, o que explica o fato de Martins dedicar uma parte importante de sua obra às questões relativas ao mundo rural brasileiro. Essas relações sociais diversas não necessariamente são antagônicas com o capitalismo brasileiro, que não as elimina, pelo contrário, as reproduz e as subordina às necessidades da acumulação do capital.

Desde esta perspectiva, o moderno não pode ser considerado apenas a superação inevitável do mundo tradicional, uma concepção muito difundida na América Latina. Na sociologia de Martins, o tradicional aparece como crítica incompleta dos efeitos e consequências da modernidade. Nas visões de cunho positivista - disse Martins o tradicionalismo dos pobres do campo migrados para as cidades, a cultura popular e a própria pobreza não fariam parte da modernidade. Nessas interpretações,

seriam manifestações anômalas e vencidas de uma sociabilidade extinta pela crescente e inevitável difusão da modernidade que decorreria do desenvolvimento econômico e da globalização (Martins: 2000: 18).

Na perspectiva de Martins, a análise da modernidade na América Latina implica o reconhecimento de sua anomalia e sua inconclusividade.

As misérias, como o desemprego e o subemprego, os valores e as mentalidades produzidos pelo desenvolvimento dependente são partes integrantes da modernidade, embora de um ponto de vista teórico e tipológico não façam parte do moderno. A modernidade só o é quando pode ser ao mesmo tempo o moderno e a consciência crítica do moderno [...]. A modernidade, nesse sentido, não se confunde com objetos e signos do moderno, porque a eles não se restringe, nem se separa da racionalidade que criou a ética da multiplicação do capital; que introduziu na vida social e na moralidade, 
até mesmo do homem comum, o cálculo, a ação social calculada na relação de meios e fins, a reconstituição cotidiana do sentido da ação e sua compreensão como mediação da sociabilidade (Martins, 2000: 18).

Martins analisa as contradições da modernidade brasileira mostrando a coexistência de tempos e relações sociais diversas; sua análise é expressão de uma concepção da história não linear, cíclica. Há uma crítica às interpretações deterministas da história e à inevitável eliminação das formas tradicionalistas, consideradas atrasadas. Essas formas tradicionalistas fazem parte da modernidade brasileira e, muitas vezes, se colocam como crítica à sociedade moderna e suas consequências. Em um de seus últimos livros - Aparição do demônio na fábrica (origens sociais do Eu dividido no subúrbio operário) (2008c) -, ele revela a presença da cultura tradicional como expressão crítica da modernidade, fazendo parte dela, porém não sendo propriamente moderna.

Ele reconstrói um fato extraordinário ocorrido numa fábrica de cerâmica que ficou guardado na memória por várias décadas. Martins trabalhou adolescente nessa fábrica e foi testemunha da aparição do demônio. Ele recorre à memória como instrumento inicial de pesquisa, anota cuidadosamente os detalhes do processo de produção e as recordações que ficaram guardadas durante muito tempo. Realizou entrevistas com algumas pessoas chave para verificar e confrontar com suas lembranças. Ele analisa esse fenômeno para mostrar a presença de relações sociais não capitalistas e da cultura tradicional que não só faz parte da modernidade brasileira, mas que se apresenta como crítica à modernidade, porém uma crítica insuficiente e limitada. Seu objetivo foi mostrar as características específicas da modernidade brasileira, estabelecendo as diferenças e as distâncias em relação a outras sociedades capitalistas.

Como se mencionou anteriormente, Lefebvre é a principal referência teórica de Martins, evidentemente não a única. Aliás, umas das marcas da sociologia brasileira de José de Souza Martins é sua abertura e a diversidade de suas fontes teóricas. Mais do que um uso específico dessas teorias, trata-se de um diálogo crítico com as ideias, os conceitos e as perspectivas de um universo de autores. Não há, em Martins, evidências de proibições como as que ainda estão presentes na academia.

Ele dialoga criticamente, se apropria de forma original de conceitos e ideias desses autores, tendo como preocupação e objeto de estudo o processo histórico de formação da sociedade brasileira. De Lefebvre, retoma uma noção fundamental: a ideia da reprodução das relações sociais. Em sua interpretação sobre a sociedade 
brasileira, tendo como base sua longa pesquisa empírica e histórica, propõe a noção de reprodução capitalista de relações não capitalistas para compreender as particularidades do capitalismo brasileiro, uma sociedade onde ainda persistem relações sociais baseadas na renda da terra e no trabalho escravo.

Nesse mesmo sentido, sua crítica ao discurso da exclusão social (Martins, 2008b; 2009) e da modernidade anômala se fundamenta na ideia de que o capitalismo brasileiro é uma totalidade inacabada e contraditória. A teoria lefebvriana dos resíduos pode contribuir para explicar essa crítica de Martins. A teoria e o método lefebvrianos dos resíduos têm sido pouco explorados pelos estudiosos do pensamento de Lefebvre. Essa teoria aparece em várias obras do autor francês, principalmente em Metafilosofia (1967), coincidentemente o seu primeiro livro publicado no Brasil. Lefebvre também é um crítico da concepção de sistema fechados. Para ele, os sistemas de poder não conseguem reduzir os resíduos que os compõem. Ele chama esses elementos de irredutíveis. Por exemplo, o poderio constituído pela religião não consegue reduzir e dominar o corpo, da mesma forma o poder do Estado é incapaz de controlar o cotidiano.

Segundo Lefebvre e Martins, na reunião desses irredutíveis existe a possibilidade de transformação social. Não foi por acaso que uma das bandeiras das revoltas de maio de 68, na França, foi a revolução do cotidiano. Os resíduos explicam a sociologia de Martins, sua crítica à modernidade brasileira, seus temas e seu método. Por isso que parte importante da sua sociologia é dedicada a temas como o rural e o cotidiano, a irracionalidade dos sonhos e da presença do mundo tradicional na modernidade brasileira. Os resíduos aparecem como base da crítica sociológica e social; da superação da alienação e também como expressão das contradições dos processos sociais e, portanto, da inovação e da repetição. E aqui toma sentido sua afirmação de que a modernidade brasileira é inconclusa, justamente para chamar a atenção das contradições da modernidade brasileira que se expressam nos resíduos. A modernidade é inconclusa e anômala porque a sua crítica aparece de forma incompleta, desencontrada e descompassada entre o moderno e a consciência crítica.

\section{Um demônio na fábrica}

O demônio aparece na fábrica de São Caetano como crítica ao moderno processo de produção e às inovações técnicas. A crítica ao moderno se transfigura de demônio, não surge como crítica racional às mudanças sociais e tecnológicas, por isso essa crítica é inconclusa e incompleta. Os ritmos desiguais do desenvolvimento capitalista aparecem na fábrica, onde formas modernas se combinam com formas atrasadas. Na fábrica de São Caetano, alguns dos setores ficaram de fora das inovações tecno- 
lógicas, combinando-se as duas formas de sujeição já referidas por Marx: sujeição real e a sujeição formal.

O capitalismo não consegue "modernizar" todos os setores de forma homogênea, por isso, alguns setores escapam à modernização. Por exemplo, no processo de trabalho da cana-de-açúcar, um setor atrasado (a produção agrícola), não modernizado, antecede à etapa industrializada do processo, isto é, moderno. Na fábrica de São Caetano, o setor atrasado, artesanal, estava situado no final das etapas modernizadas. Ele se refere ao setor da escolha e classificação dos ladrilhos, como sendo atrasado, artesanal, mas que também era alcançado pela modernização tecnológica, indiretamente, através do ritmo intenso de trabalho,

o momento artesanal do processo de trabalho foi criado pela própria grande indústria, na falta de recursos técnicos que compatibilizassem o trabalho de escolha e classificação dos ladrilhos com os outros momentos do processo de trabalho (Martins, 2008c: 170).

Martins encontra no invisível e na anomalia, como é o caso da aparição do demônio, a chave para explicar as características da modernização e suas relações com a modernidade.

A modernização do processo de trabalho na fábrica implicou também a imposição e disseminação do conhecimento técnico dos engenheiros que entrou em contradição com o saber dos mestres que eram portadores de concepções e valores tradicionais. Eles eram representantes de um mundo que estava desaparecendo. A modernização na fábrica de São Caetano estava implantando uma nova divisão de trabalho que separava o trabalho intelectual do trabalho manual, porém esse processo é desigual, e na seção de escolha e classificação, que era principalmente formado por mulheres trabalhadoras, não tinha sido alcançado diretamente por essas modificações e inovações tecnológicas. O trabalho na seção de escolha dependia principalmente das habilidades das trabalhadoras, porém o ritmo de trabalho era imposto pelas máquinas e a tecnologia das etapas anteriores do processo de trabalho. Então, Martins aponta uma contradição fundamental entre o ritmo imposto pelas máquinas nas etapas anteriores e o trabalho na seção de escolha. Foi nesse desencontro de ritmos que o demônio se fez visível para as mulheres da seção de escolha.

Os ladrilhos estavam saindo rachados e com defeitos do novo forno. Porém do velho forno, 90\% dos ladrilhos não só saiam sem defeitos, mas eram de primeira qualidade. Para os engenheiros, a situação devia se resolver apenas com ajustes nas novas máquinas. Para as operárias, era um momento de incerteza que escapa- 
va ao controle, e interpretaram a situação de outro modo: elas atribuíram os ladriIhos defeituosos à presença do demônio e, precisamente por isso, elas se sentiram ameaçadas.

Ele era visto meio sorridente, bem vestido, como os engenheiros, num canto da seção. As operárias alegavam, também, que nos momentos em que ele aparecia, sentiam cheiro de enxofre, um cheiro que a cultura popular associa à figura de Satanás. A contramestre da seção, era uma senhora muito católica, moradora no bairro vizinho à fábrica em que também moravam as operárias [...]. Alegavam as operárias que o demônio estava ali presente porque a fábrica começara a funcionar antes de receber a bênção do padre (Martins, 2008: 173-174).

Martins explica sociologicamente a aparição do demônio: sua presença tornou visível as modificações tecnológicas e a intensificação do ritmo de trabalho que se apossaram do corpo das trabalhadoras, mas também salienta que há na visão das trabalhadoras uma determinada concepção de riqueza. Para elas, a riqueza é pagã e se constitui em negação da humanidade do trabalhador que a produz, ao mesmo tempo em que se descobre separado de sua obra. A crítica à inconclusividade da modernidade brasileira é uma das formas em que aparece o tema de alienação na sociologia de Martins. Um tema central na obra de Marx e Lefebvre.

Na aparição do demônio na fábrica, a crítica da alienação se apresenta de forma incompleta e inconclusa, sua "superação" - ou a "desalienação" - é inconclusa porque é resolvida através de rituais da cultura tradicional e religiosa das populações rurais, porque reconcilia os antagonismos legitimando-os. É por isso que a modernidade é inconclusa, porque a crítica é limitada, baseada em valores tradicionais, e essa combinação entre o moderno e o tradicional, que aqui aparece como consciência incompleta, é contraditória. Em outras palavras, Martins distingue o moderno, ou seja, o novo, as tecnologias, as máquinas, e a modernidade, que supõe, além do novo, também uma consciência crítica do moderno.

É o rito da bênção dos locais, meios e condições da produção que reconcilia simbolicamente o trabalhador com seu produto. Legitimando, porém, o antagonismo que os confronta. De fato, celebrada a missa e benzidas as instalações, com a presença dos proprietários, dos engenheiros, mestres e de todos operários, inclusive os das velhas seções das duas divisões da fábrica, o demônio não se fez mais visível. Nesse meio tempo, foi descoberta a causa dos defeitos nos ladrilhos, que passaram a ser produzidos com a qualidade tradicional (Martins, 2008c: 174). 
Num trabalho anterior sobre a obra de Martins, argumentei que, em minha interpretação, duas eram as noções centrais que possibilitam compreender a sociologia e a concepção de história de Martins: as noções de resíduos e a de menos-valia. Como já foi dito, a primeira pertence a Lefebvre; a segunda, surpreendentemente, a Marx.

\section{Os resíduos e os poderios}

Os resíduos, apontados por Lefebvre, envolvem uma potência constituída em "mundo" e um largo alcance explicativo. Os resíduos são, em termos teóricos e metodológicos, uma grande descoberta, que, apropriados criticamente por Martins, são transformados, enriquecidos e reconstruídos de forma original e inovadora. Esses resíduos e o residual constituem uma das chaves explicativas da obra de Martins. Descartados por outras interpretações, os resíduos tornam-se os elementos essenciais para compreender sua sociologia.

Martins reúne os resíduos dispersos produzidos no processo histórico de constituição da sociedade brasileira, descobre que o residual contém potencialidades esclarecedoras sobre o possível oculto nas misérias e injustiças sociais do presente. A teoria dos resíduos de Lefebvre permite compreender os temas tratados por Martins: a visão das crianças sobre o mundo dos adultos, o silêncio, o não dito e o indizível, os sonhos (Martins, 1996a), os desencontros da modernidade e do moderno, a vida cotidiana e a alienação, os tempos e ritmos diferentes das relações sociais que não se excluem, apesar de estarem em contradição.

Segundo Lefebvre (1967), é nos resíduos que há possibilidade de resistência e transformação. Como já foi dito, os sistemas deixam um resíduo que, irredutível, deles escapa. Lefebvre se refere especialmente ao estruturalismo que pretende fundar um sistema. Mas recua, se enfraquece, e deixa um resíduo que dele escapa: o tempo. É o tempo que distingue as conexões das formas que nele se realizam. Nos resíduos, existem as possibilidades de criar, do novo. Mesmo a matemática não constitui um sistema fechado, nela há a possibilidade de criação. A matemática produz um resíduo: o drama que escapa ao número, mas que o ilumina, esclarecendo-o. Nas palavras de Lefebvre, "a diversidade dos resíduos e seu caráter residual só tem sentido nos e pelos sistemas que tentam reabsorvê-los" (Lefebvre, 1967: 374). Do que se conclui que os resíduos contêm significativas potencialidades teóricas e metodológicas para compreender os sistemas de poder e que estes sistemas não são fechados. Lefebvre é um crítico radical da noção de sistema entendida como totalidade acabada e fechada. Crítica que é compartilhada por Martins que, como já foi dito, considera o capitalismo brasileiro como uma totalidade inacabada. 
A teoria dos resíduos de Lefebvre retoma o tema do romantismo, mas dando-lhe um novo sentido, isto é, o tema da negatividade, da contestação e da crítica radical. O método lefebvriano busca, em primeiro lugar, detectar os resíduos, apostar e mostrar neles a sua essência, reuni-los e organizar suas revoltas. Um resíduo é um irredutível que deve ser apreendido novamente.

Neste sentido também pode compreender-se a obra de Martins, isto é, a partir do residual ele cria uma nova sociologia e uma nova prática sociológica. O primeiro passo - disse Lefebvre - é reunir os resíduos que são depositados pelos sistemas que procuram inutilmente constituir-se em totalidades. A religião não consegue acabar com a vida carnal e a vitalidade espontânea. A filosofia deixa escapar o elemento lúdico e cotidiano, que não é capaz de absorver. Assim como o drama escapa à matemática, a estrutura e o estruturalismo deixam novos resíduos: o tempo, a história, o particular e as particularidades específicas. A máquina e a técnica mostram aquilo que Ihe resiste: o sexo e o desejo; o Estado é implacável contra a liberdade, mas a qualifica. A centralidade do Estado salienta a descentralização irredutível das regiões. A arte deixa um resíduo, a criatividade. A burocracia não consegue reduzir o indivíduo, o singular, assim como a organização não pode eliminar o espontâneo e o desejo. Esses são os irredutíveis.

O método dos resíduos de Lefebvre não mostra uma imagem enganadora do futuro, mas apela para o possível, para a imaginação. Ao partir do atual, sem descuidar do imprevisível, o método lefebvriano presta atenção ao novo que surge na história. Os resíduos não são só o mais precioso, mas fazem explodir por dentro os sistemas que querem absorvê-los.

Nesse sentido, a poiésis, que deles se apodera, deve revelar-se criadora de objetos, de atos e, mais geralmente, de situações (Lefebvre, 1967: 377).

Martins, do mesmo modo que Lefebvre, constrói sua sociologia a partir daquilo que não tem valor, ou que não tem mais valor, isto é, o cotidiano, a ambiguidade, a palavra incerta. Esses são os resíduos a que se refere Lefebvre e que estão presentes na sociologia de Martins.

É do residual do qual parte a poiésis, isto é, as potencialidades da criação. As imensas possibilidades tecnológicas atuais - disse Lefebvre - chegam às pessoas como resíduos daquilo que foi destinado à alimentação dos sistemas de poder. Um exemplo típico é a internet, da qual hoje se beneficiam milhões de pessoas mundo afora. Em sua origem destinada a alimentar o sistema militar, chega de forma residual às pessoas, que a utilizam, a potencializam e transformam. 
Os estudos de Martins sobre as populações camponesas (Martins, 1981) buscam encontra no residual as possibilidades de interpretação sociológica da sociedade brasileira. Lefebvre também fez seu doutorado em sociologia rural. Nessa pesquisa, ele fez a reconstituição de mil anos de história de uma aldeia francesa, encontrando o significado dos confrontos políticos centenários e de concepções de vida que não poderiam ser identificadas a partir de uma perspectiva evolucionista e linear. Assim, tanto para Martins como para Lefebvre, o rural possui uma riqueza metodológica que não existe em outros lugares. É no mundo rural que existe uma maior diversidade e tensão de tempos históricos e relações sociais.

\section{A noção de menos-valia}

A teoria de Marx tem na noção de mais-valia sua contribuição mais importante, superando com ela, a teoria de Adam Smith e David Ricardo. A preferência metodológica de Martins pelo residual e marginal o leva a descobrir uma noção aparentemente sem importância, numa linha perdida de $O$ capital: é a noção de menos-valia. Uma noção que é marginal e que nenhum dos seguidores de Marx prestou atenção. A noção de menos-valia é, a meu ver, a melhor manifestação da concepção não linear da história, da combinação de temporalidades e relações sociais diferentes, presentes na sociologia de José de Souza Martins, atento às coisas desimportantes, àquilo que parece secundário, oculto, capaz de descobrir uma noção oculta no pensamento de Marx, mas que é reveladora de uma particular interpretação da história e do desenvolvimento desigual do capitalismo em sociedades como a brasileira.

A noção de menos-valia aparece num livro de fotografia, aparentemente desimportante de Martins (2008a), por isso, despercebida. A desimportância do livro é apenas aparente, na introdução intitulada reveladoramente "Retratos do silêncio", ele se refere a essa noção perdida em Marx. Ao resgatar a noção de menos-valia, a confronta com a noção mais conhecida pelos marxistas: a mais-valia. Mostra que, em Marx, há uma concepção não linear da história que se expressa na noção de menos-valia. As noções de resíduo e menos-valia se constituem num caminho para a construção de uma interpretação e de uma compreensão de sociologia de Martins. Evidentemente não é o único, mas é o caminho interpretativo que proponho neste texto. A noção de menos-valia, salienta Martins (2008a), se apresenta como contraponto da tentação de linearidade da história, expressão do que de residual há na história, bem como manifestação da temporalidade do social. Nas palavras do autor:

Numa linha perdida de um dos três volumes de O capital, de passagem, Karl Marx usa a noção de menos-valia. Num denso e inacaba- 
do livro sobre a mais-valia, a exploração do homem pelo homem, a forma social de extração e acumulação da riqueza na sociedade contemporânea, a fonte da imensa massa do capital que transfigurou a sociedade, fonte do poder que os circunda e nos conforma, essa referência é o contraponto dialético à tentação de linearidade, do discurso meramente conceitual, do modo único de dizer e de compreender (Martins, 2008a: 9).

É, portanto, nos resíduos da história e do social que Martins encontra as referências para sua sociologia enraizada, no menos que significa mais, naquilo que parece insignificante, mesmo não sendo, no homem simples que não se considera ator da história, embora seja, mas que se encontra alienado e dividido.

Abstract: In this paper, the author examines the sociology of José de Souza Martins by focusing on his theoretical perspective and dialectical method. Martins addresses what is on the edge of society and the Social Sciences, which includes, for instance, the fate of rural people, the dreams of workers in large cities, the apparition of the devil in a factory, and the everyday life of ordinary men. Disciple of Florestan Fernandes, Martins establishes a dialog with Marx and Lefebure from whom two essential notions are taken: those of capital loss and residue. The author of this article points out that these two notions, seemingly insignificant, are key to understanding the contribution of Martins. In Martins' Sociology, what is in on the edge is not just a theme, but it is also and primarily a methodological resource.

Keyword: capital loss, residue, sociology, history, dialectical method

\section{Referências}

LEFEBVRE, Henri. Tiempos equívocos. Barcelona: Editorial Kairós, 1976.

. A re-produção das relações de produção. Porto: Publicações Scorpião, 1973.

—. Metafilosofia. Rio de Janeiro: Civilização brasileira, 1967.

MARTINS, José de Souza. A sociologia como aventura - memórias. São Paulo: Contexto, 2013.

- O cativeiro da terra. São Paulo: Contexto, 2010.

——. Exclusão social e a nova desigualdade. São Paulo: Paulus, 2009.

—. José de Souza Martins. São Paulo: Editora Universidade de São Paulo, 2008a.

- A sociedade vista do abismo (Novos estudos sobre a exclusão, pobreza e classes sociais). Petrópolis: Vozes, 2008b. 
- A aparição do demônio na fábrica (origens sociais do Eu dividido no subúrbio operário). São Paulo: Editora 34, 2008c.

—. A sociabilidade do homem simples. São Paulo: Hucitec, 2000.

_- (Org.). (Des)figurações: a vida cotidiana no imaginário onírico da metrópole. São Paulo: Hucitec, 1996a.

- (Org.). Henri Lefebvre e o retorno à dialética. São Paulo: Hucitec, $1996 \mathrm{~b}$.

. Os camponeses e a política no Brasil. Petrópolis: Vozes, 1981.

—. Capitalismo e tradicionalismo. São Paulo: Livraria Pioneira Editora, 1975. 